\title{
ANDRAGOGIA COMO METOLOGIA DE TREINAMENTO E DESENVOLVIMENTO EM SEGURANÇA DO TRABALHO
}

\author{
Robson Cupertino de Lima $^{1}$ \\ Leandro Oliveira de Menezes ${ }^{2}$
}

\begin{abstract}
RESUMO
Dentro do ambiente corporativo, cada vez mais competitivo, o desenvolvimento dos profissionais no local de trabalho deve ser contínuo, sendo assim, é fundamental que colaboradores sejam treinados através de práticas de ensino andragógicas, ou seja em um modelo de ensino de adultos, onde a educação é de responsabilidade compartilhada entre professor e aluno. Em se tratando dos treinamentos em Segurança do Trabalho, este modelo torna-se relavante, tendo em vista que a não efetividade do aprendizado pode representar riscos à vida e ao patrimônio. Nesse sentido, surge, então a problemática do presente estudo: Em que nível a atuação dos instrutores em Segurança do Trabalho se aproximam ou se distanciam em relação às práticas Andragógicas. Os objetivos do presente estudo são: identificar o nível de aproximação/distanciamento que a atuação dos instrutores em Segurança do Trabalho está com relação à perspectiva andragógica; verificar como os instrutores utilizam a metodologia andragógica; analisar a utilização de técnicas e métodos no processo de ensino aprendizagem a partir da visão andragógica; e apresentar vantagens quanto ao uso adequado e estruturado da metodologia andragógica nos treinamentos e capacitações dentro das empresas. A pesquisa se desenvolveu, através de questionário, tendo como sujeitos de pesquisa 10 instrutores de Segurança do Trabalho atuantes em empresas de grande porte da indústria. $O$ estudo concluiu que os instrutores precisam acrescentar técnicas andragógicas às suas atividades e precisam entender melhor como funciona o aprendizado de adultos.
\end{abstract}

Palavras-chave: Andragogia. Segurança do Trabalho. Educação de Adultos.

\section{INTRODUÇÃO}

A Andragogia é um modelo de educação de adultos, onde as experiências de vida dos alunos são utilizadas como meio para a aprendizagem do conteúdo ensinado. É diferente da pedagogia, onde o professor se posiciona como aquele que distribui conhecimento a partir da sua própria análise, sem utilizar como meio de

\footnotetext{
1 Robson Cupertino de Lima - Especialista em Segurança Comportamental; Pós-graduado em Psicodrama (PUC-SP); Especialização em Andragogia e Educação de Adultos (FADBA); Graduado em Educação (USJT). E-mail: robson.cupertino@hotmail.com

${ }^{2}$ Leandro Oliveira de Menezes - Mestrando em Estudos Territoriais (UNEB); MBA em Administração e Qualidade (UNINTER); Especialista em Metodologia do Ensino Superior (UNINTER) e Educação a Distância (ESAB); Bacharel em Administração (UEFS) e Licenciado em História (UEFS). Atualmente é professor da FADBA. E-mail: 4menezes@gmail.com
} 
ensino as experiências de vida dos alunos, já que esses estão em processo de formação, por serem crianças.

Os adultos carregam consigo experiências de vida e aprendem com os próprios erros, e isto não deve ser desprezado no processo de ensinoaprendizagem, pelo contrário, deve ser um dos pilares. É a partir dessa premissa que surge a Andragogia, onde a educação é vista como responsabilidade compartilhada entre professor e aluno.

A educação de adultos está em diversos espaços, formais e informais. Dentre elas estão as formações continuadas dentro das organizações. Algumas empresas chegam até a manter uma universidade corporativa incentivando estudos autônomos e/ou compartilhados, presenciais e/ou à distância, de modo a contribuir com a motivação dos trabalhadores, mas, sobretudo, pela expectativa de melhoramento das práticas.

$\mathrm{Na}$ Segurança do Trabalho é fundamental que os cursos profissionais sejam ministrados mediante técnicas andragógicas, já que o ambiente organizacional está cada vez mais complexo e focado na produtividade, exigindo que todos estejam bem treinados para executar suas atividades de forma eficiente. Em outras palavras, o fato de que as aprendizagens esperadas nos treinamentos em Segurança do Trabalho objetivam a proteção dos indivíduos dentro das empresas/indústrias, exige que as metodologias e ferramentas utilizadas pelo instrutor sejam eficientes.

Portanto, cabe o seguinte problema de pesquisa: Em que nível a atuação dos instrutores em Segurança do Trabalho se aproximam ou se distanciam em relação às práticas Andragógicas?

O objetivo geral do presente estudo é identificar 0 nível de aproximação/distanciamento que a atuação dos instrutores em Segurança do Trabalho está com relação à perspectiva andragógica.

Os objetivos específicos do trabalho são: verificar como os instrutores utilizam a metodologia andragógica; analisar a utilização de técnicas e métodos no processo de ensino aprendizagem a partir da visão andragógica; e apresentar vantagens quanto ao uso adequado e estruturado da metodologia andragógica nos treinamentos e capacitações dentro das empresas.

Tal estudo possui relevância social, acadêmica e pessoal. Sua importância no nível social está atrelado ao fato, já citado anteriormente, de que se a perspectiva andragógica for utilizada nos treinamentos em Segurança do Trabalho, é possível 
ser mais eficiente no alcance dos objetivos, e isto reverberará em práticas, dentro das organizações, que podem evitar situações que colocariam vidas em risco. Assim como tornar os momentos de formação mais prazerosos, e participativos, tendo em vista que os estudantes adultos são convidados a trazer à aula suas experiências de vida.

No nível acadêmico, observamos que ainda são poucos os estudos científicos, pelo menos no Brasil, que abordam a Andragogia. E se tivermos tratando da relação Andragogia-Segurança do Trabalho, a carência apresenta-se ainda mais notória. É preciso, portanto, incentivar mais estudos que tratem desta temática, de modo a contribuir com o melhoramento nos processos de ensino que envolvam adultos, em suas mais diferentes localidades e objetivos. Um breve estudo como este, pode sugerir outros estudos, pode apresentar a temática àqueles que a desconhecem, assim como pode indicar possíveis referências a outros pesquisadores.

Este estudo, se torna justificável também, devido à minha relação profissional com a temática, pois sem ela não teria conhecido a Andragogia, não perceberia a sua importância, e nem me sentiria instigado a estudá-la. Minha relação com a área de Segurança do Trabalho, mais especificamente no ramo de Segurança Comportamental, data de 2007. E foi, somente após um treinamento, em que o instrutor falou dos princípios andragógicos que, pela primeira vez, ouvi falar da temática, e seus princípios.

Desde então comecei a pesquisar, estudar e utilizar os conceitos andragógicos nos meus treinamentos e processos de aprendizagem. Ao utilizar estes conceitos percebia que os treinamentos se tornavam mais interessantes e os aprendizes em geral demonstravam maior interesse. Entretanto, conhecia as minhas limitações; e, consciente delas, matriculei-me no curso de especialização em Andragogia e formação de adultos, pela Faculdade Adventista da Bahia, de modo a me aprofundar nos conceitos, técnicas e ferramentas andragógicas.

O conhecimento desta metodologia fortaleceu as minhas convicções de que o modelo de educação que eu usava e que muitos instrutores utilizam, não proporciona e nem incentiva aos alunos na busca pelo autoconhecimento, de forma que se possa relacionar a teoria com as vivências e experiência pessoais e profissionais dos aprendizes, daí surgiu meu interesse pela problemática deste estudo. 
E para alcançar os objetivos propostos nesta pesquisa, optou-se pela abordagem mista. É uma pesquisa de caráter exploratória, cuja técnica de coleta de dados primários foi o questionário direcionado a instrutores de Segurança do Trabalho.

O trabalho está dividido do seguinte modo: após esta introdução, há uma breve discussão teórica sobre a Andragogia, seus princípios e desdobramentos; posteriormente, as explicações do percurso metodológico; as análises dos resultados; e, por fim as considerações finais.

\section{REFERENCIAL TEÓRICO}

\subsection{Andragogia: uma necessidade para quem?}

A pedagogia originou-se no começo do século VII, na Europa. Surgiu nas escolas de educação infantil e é utilizada até hoje. De acordo com De Carvalho (2010), as crianças são seres dependentes que necessitam de cuidados constantes. Já os adolescentes, são questionadores e os adultos acumulam certas experiências, aprendem a aprender com os próprios erros e adquirem a consciência de que ainda é necessário aprender. É nesse sentido que surge a Andragogia, que é um modelo de ensino de adultos, onde a educação é de responsabilidade compartilhada entre professor e aluno.

Paralelamente, o ambiente organizacional cada vez mais complexo e focado na produtividade, exige que os colaboradores sejam muito bem treinados para executar suas atividades de forma eficiente e sabendo dos riscos laborais a que estão expostos. Concorda Tardif (2000), ao ressaltar que, tanto nas suas bases teóricas quanto nas práticas, o conhecimento que profissionais adquirem no mercado de trabalho são evolutivos e progressivos.

Tardif (2000) ainda afirma que o desenvolvimento constante de profissionais no meio de trabalho necessita ser mantido através de formação contínua. Sendo assim, é fundamental que colaboradores sejam treinados através de práticas de ensino fundamentadas, como é o caso da Andragogia.

Em estudo publicado Oliveira (2010, apud BRESSIANI E ROMAN, 2016), pôde ser observado que muitos cursos de treinamentos de profissionais adultos no 
ambiente de trabalho não incentivam a aprendizagem e isso pode acarretar a falta de sucesso desses trabalhadores. Sendo assim, a disseminação de metodologias de ensino para adultos, como a Andragogia, é fundamental para o bom desenvolvimento dos profissionais.

\title{
2.2. Conceito e características da Andragogia
}

Apesar do termo Andragogia ainda ser desconhecido para a maioria dos profissionais que atuam em educação, ele está longe de ser um termo novo, tanto quanto as suas práticas. Para uma melhor compreensão do conceito é importante destacar que ela se difere da Pedagogia em diversos aspectos, talvez o principal deles seja o fato de a Andragogia ser direcionada a adultos, enquanto a pedagogia se refere ao ensino de crianças, como já citado no item anterior.

Beck (2014) destaca que os métodos de ensino que são usados na pedagogia se baseiam mais na passagem de conhecimento fundamental. Ela não se resume a discutir a prática ou a aplicabilidade do saber. Ainda, segundo o autor, a educação de adultos, talvez o conteúdo que o professor pretenda transmitir (com base em um currículo pré-definido) já seja de conhecimento do aluno e a necessidade seja de entender em como aplicá-lo em sua realidade pessoalprofissional.

Barros (2018) ressalta que

\begin{abstract}
No modelo andragógico parte-se do pressuposto de que o principal fator de motivação do educando adulto é de ordem interna. Ou seja, a motivação num caso pode ser condicionada do exterior mais facilmente que no outro, supondo-se a criança como um ser aberto e o adulto como um ser fechado sobre si, a quem cabe automotivar-se para aprender (BARROS, 2018, p. 05).
\end{abstract}

Ou seja, o adulto, busca ser protagonista do seu aprendizado, trazendo para o ambiente de ensino as suas experiências de vida. Durante o processo de aprendizagem do adulto, é importante que o educador se coloque disponível e se envolva com essa questão para obtenção de resultados e soluções dos problemas que afetam e colocam dificuldades/barreiras. Os adultos conseguem acessar seus conhecimentos, experiencias, e sentimentos prévios com maior consciência, diferentemente das crianças. 
É preciso que se resgate o respeito ao homem adulto, como condição de sua cumplicidade, responsabilidade e comprometimento com os objetivos da organização e do seu papel profissional no processo de ensino/aprendizagem. Por estar diretamente conectada com a qualificação profissional, Bressiani e Roman (2016) destaca que a experiência profissional é elemento basilar dos métodos educativos andragogicos.

De acordo com Henschke (1998 apud BRESSIANI e ROMAN, 2016), a Andragogia busca identificar as formas com que os adultos aprendem e envolvê-los em um processo metodológico claro de ensino. O cerne da Andragogia é buscar a participação dos alunos, que são incentivados a expor suas experiências de vida. Neste sentido, "A aprendizagem de adultos tende a ser mais complexa em função das variáveis que a influenciam, como estilos de ensino, motivação para participar, questões culturais, autoestima, experiências de aprendizagem e problemas pessoais" (BRESSIANI e ROMAN, 2016, p. 03).

\subsubsection{PRINCÍPIOS DA ANDRAGOGIA}

De acordo com Chan (2010), existem seis princípios da Andragogia. São eles:

- Autoconceito do aprendiz: diferentemente da criança, o adulto se auto responsabiliza por suas decisões, sobre sua vida. Ele sente a necessidade de ser tratado como um ser humano que se autodirige. Ou seja, não aceita imposição de vontades de outrem.

- O papel da experiência do aprendiz: o aluno já carrega experiências pessoais prévias, acumuladas ao longo da sua vida adulta. $O$ adulto sente vontade de aplicar essas experiências na sala de aula para participar do ambiente de aprendizado.

- Prontidão para aprender: os adultos se prontificam para aprender sobre assuntos que precisam se tornar capazes de realizar.

- Orientação da aprendizagem: os interesses dos adultos se direcionam para o desenvolvimento de habilidades que são utilizadas em seu cotidiano profissional.

- A necessidade de conhecimento: os adultos precisam saber qual o motivo de estarem aprendendo determinado conteúdo. Precisam ver 
sentido prático no aprendizado. Com isso, querem que o aprendizado seja significativo do ponto de vista prático.

- A motivação para aprender: o adulto é guiado por motivações internas (autoestima, maior qualidade de vida, desejo deter maior satisfação no trabalho), as quais são mais importantes para eles do que as externas (melhores empregos, promoções, salários maiores).

Todo educador que se pretenda se aproximar dos preceitos Andragógicos deve atentar-se a estes princípios, tendo em vista que o aprendizado do adulto precisa ser dinâmico e incluir as experiências dos alunos dentro da didática.

Profissionais em cargos de liderança costumam notar, normalmente que, mesmo quando abordam assuntos importantes, as apresentações, mesmo que de boa qualidade, nem sempre conseguem treinar de forma objetiva. Provavelmente, a forma com que o conteúdo é passado carece de técnicas andragógica, muitas vezes, já que a maioria das empresas segue, intencionalmente ou não, as diretrizes da Pedagogia tradicional, onde o instrutor é o centro da aprendizagem.

\title{
2.1.2 O PERFIL E O PAPEL DO ANDRAGOGO
}

O educador que utiliza as ferramentas, metodologias e princípios Andragógicos no desenvolvimento de suas atividades é chamado de Andragogo. Para que possa fazer jus a este título, o profissional precisa utilizar técnicas que coloquem o aluno no centro do ensino e não o professor, como acontece na Pedagogia.

Como ressalta Mercúrio (2017),

\begin{abstract}
A Educação Corporativa vem sido cada vez mais aplicada pelas organizações, visando capacitar seus colaboradores. Mas nem sempre conquista resultados, pois na maioria das vezes, ocorre é o uso da pedagogia, que é voltada para crianças, no processo de desenvolvimento, por isso o aprendizado não se consolida de forma eficaz (MERCÚRIO, 2017, p12)
\end{abstract}

Na pedagogia tradicional o professor é o centro detentor do conhecimento e os alunos comportam-se de forma meramente passiva, assimilando aquilo que é exposto. Já o perfil andragógico coloca os alunos como parte agregadora do conhecimento. 
Mercúrio (2017) ainda afirma que "o modelo andragógico indica que uma grande parte da responsabilidade do aprendizado é do próprio aluno, transformando o papel de professor em facilitador de aprendizagem, conduzindo ao sucesso e estimulando resultados" (MERCÚRIO, 2017, p. 01)

A figura 01 , a seguir, ilustra bem essa diferença.

Figura01 - Diferenças entre Pedagogia e Andragogia

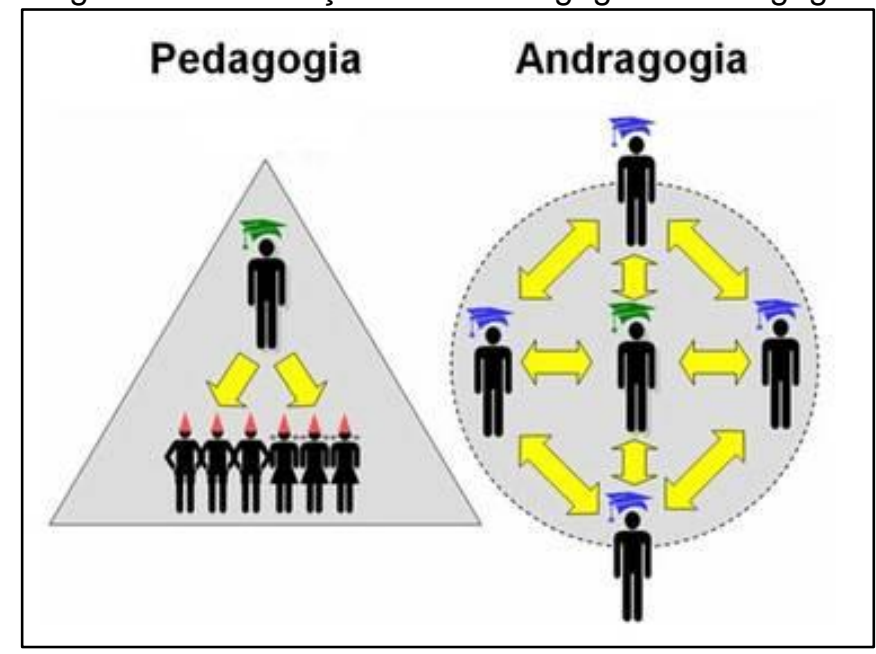

Fonte: Mercúrio (2017)

Knowles (1986), ao defender o que chama de prática moderna da educação de adultos, referindo-se aos contratos de aprendizagem que se deve fazer com os aprendizes, sugere etapas, que podem contribuir para um caminhar dos pretendentes a andragogos.

A primeira etapa que ele sugere é a etapa de diagnóstico das necessidades de aprendizagem, baseia-se na definição do estado onde você está agora e onde você quer estar; depois a especificação dos objetivos de aprendizagem, ou seja, definir o que se quer aprender; posteriormente, sinaliza que deve haver a especificação dos recursos e estratégias de aprendizagem; em seguida, especificação dos prazos, das evidências de realização (quantitativas e/ ou qualitativas), da especificação de como a evidência será validada; e, por fim, as etapas de revisão e execução do contrato e a avaliação da aprendizagem.

Ou seja, para que os instrutores utilizem da Andragogia como técnica de ensino, é importante que eles conheçam as características dos alunos e as suas necessidades, pois, num ambiente andragógico, a vivência e as experiências dos alunos são de suma importância para adotar uma metodologia de ensino útil a todos os envolvidos. 


\section{METODOLOGIA}

O dicionário online Michaelis esclarece que pesquisar tem o significado de buscar, indagar, inquirir e investigar. Paralelamente, Minayo (2003) destaca que a pesquisa é uma atividade básica das ciências que buscam a realidade. A pesquisa é também uma atitude prática teórica de constante procura que define um processo inacabado e permanente.

O presente estudo tem caráter exploratório. Gil (1999) define que as pesquisas exploratórias tem por finalidade esclarecer, desenvolver e modificar ideias e conceitos, envolvendo levantamento bibliográfico, documental, entrevistas e estudos de caso, tendo como principal técnica, a coleta de dados.

Essa pesquisa teve como foco analisar a aproximação ou distanciamento da atuação dos instrutores em Segurança do Trabalho em relação às práticas Andragógicas, portanto é também uma pesquisa de caráter misto, apresentando uma abordagem mais quantitativa, em que os dados sociais foram transformados em dados numéricos, e uma qualitativa que nos permitiu interpretar estes dados para além de seu estado factual.

Paralelamente ao que ressalta Gil (1999), Johnson (2007), define a pesquisa mista como aquela que não sugere uma limitação à combinação de métodos apenas. $\mathrm{O}$ autor define esse tipo de pesquisa da seguinte forma:

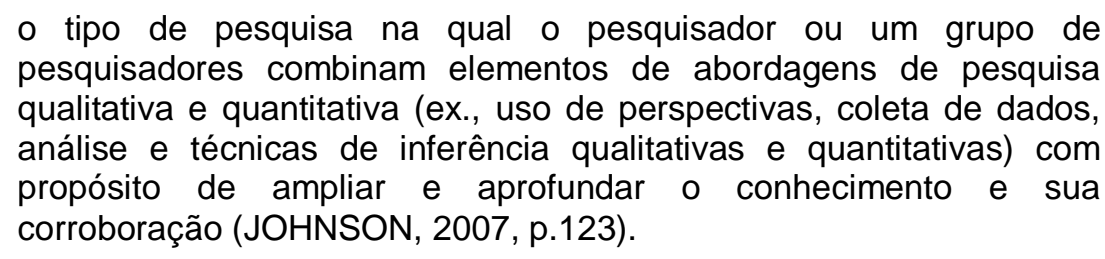

A técnica de coleta de dados primários escolhida foi o questionário. Os questionários foram elaborados com 15 perguntas de múltipla-escolha e abordaram questões concernentes à atividade de instrução dos profissionais. Cada questão exigia do respondente assinalar uma alternativa em uma escala numérica que variava de 0 a 10. Após a aplicação, os dados foram agrupados para se obter médias para cada item avaliado e foi realizado o cálculo de NPS ${ }^{3}$ da amostra.

\footnotetext{
${ }^{3}$ Também conhecido como Net Promoter Score. Metodologia utilizada em grandes empresas por todo o mundo para medir a satisfação e lealdade dos clientes, o que ajuda a identificar problemas no negócio. Essa metodologia foi criada em 2003 por Fred Reichheld, diretor da renomada empresa de consultoria e gestão Bain\&Company (PRADO, 2019).
} 
O instrumento foi produzido, inspirado em Bressianie Roman (2016), e nos pressupostos de Knowles (1986), para a prática moderna da educação de adultos.

Foram escolhidos 10 instrutores de Segurança do Trabalho (técnicos ou engenheiros de segurança), da cidade de São Paulo - SP, atuantes na indústria, há pelo menos 5 anos. A escolha de 10 empresas e de 10 instrutores se deu por livre escolha do autor, sem utilizar critério amostral. Por outro lado, foi definido um perfil de respondente para fazer parte desta pesquisa. As características exigidas foram: estar empregados em empresas que possuem grau de risco igual ou maior que três (conforme quadro I da NR-4 do ministério do trabalho, lei 6.514) e que possua sistema estruturado em Segurança do Trabalho (certificação ISO 18.001/45.001); atuar a mais de 5 anos, e que desempenhem diretamente, além de outras funções da área, treinamentos técnicos e comportamentais.

\section{ANÁLISE DOS RESULTADOS}

A análise dos dados ocorreu a partir do cálculo NPS. E, segundo Prado (2019), a média de um bom NPS pode variar de acordo com o ramo de atuação e o segmento da empresa, mas, de forma geral, existe a seguinte escala de classificação:

- NPS entre 75 e 100 - Excelente: esse valor é raramente alcançado. Quando a empresa atinge esse nível, significa que a empresa é referência em seu mercado.

- NPS entre 50 e $\mathbf{7 4}$ - Muito bom: normalmente também é difícil de ser alcançado. É um grande desafio para as empresas serem referências em seus mercados.

- NPS entre 0 e 49 - Razoável: o nível razoável exige grandes cuidados da empresa. Aqui o trabalho de imagem deve ser prioridade, já que as chances de modificar o NPS são maiores.

- NPS entre -100 e -1 - Ruim: ter um NPS entre -1 e -100 é um grande problema para a empresa. É necessário tomar uma ação emergencial para reverter esse quadro.

A seguir são ilustrados os resultados obtidos através dos questionários enviados aos instrutores. 
Tabela 1- Média e NPS

\begin{tabular}{|c|c|c|c|}
\hline № & QUESTÕES & MÉDIA & NPS \\
\hline 1 & $\begin{array}{l}\text { No início do treinamento, eu identifico as necessidades e } \\
\text { expectativas dos aprendizes? }\end{array}$ & 6,2 & $-50 \%$ \\
\hline 2 & $\begin{array}{l}\text { Eu deixo claro logo no início as vantagens e benefícios que o } \\
\text { treinamento proporcionará? }\end{array}$ & 5,6 & $-60 \%$ \\
\hline 3 & $\begin{array}{l}\text { Em algum momento eu permito que os alunos indiquem o que } \\
\text { gostariam de aprender? }\end{array}$ & 3,1 & $-100 \%$ \\
\hline 4 & $\begin{array}{l}\text { Logo no início do treinamento eu procuro identificar o estilo de } \\
\text { aprendizagem dos alunos, ou seja, os que são visuais, auditivos ou } \\
\text { cinestésicos? }\end{array}$ & 2 & $-100 \%$ \\
\hline 5 & $\begin{array}{l}\text { Eu consigo despertar o interesse pessoal do trabalhador em } \\
\text { aprender sobre o assunto que estou ensinando? }\end{array}$ & 6,5 & $-40 \%$ \\
\hline 6 & $\begin{array}{l}\text { Eu exploro as vivências e experiências profissionais do trabalhador } \\
\text { associando com o que é apresentado? }\end{array}$ & 5,8 & $-80 \%$ \\
\hline 7 & $\begin{array}{l}\text { Eu consigo demonstrar ao trabalhador que o assunto que ele irá } \\
\text { aprender vai atender suas necessidades básicas e será de } \\
\text { aplicação imediata e em situações reais? }\end{array}$ & 7 & $-20 \%$ \\
\hline 8 & $\begin{array}{l}\text { Quando o trabalhador manifesta traços da sua cultura, valores e } \\
\text { comportamentos, eu proporciono reflexão e análise de todo o grupo, } \\
\text { facilitando o processo de aprendizagem? }\end{array}$ & 4,8 & $-90 \%$ \\
\hline 9 & $\begin{array}{l}\text { Tudo que eu apresento no treinamento é de extrema importância e } \\
\text { agrega valor real ao desempenho da função do trabalhador? }\end{array}$ & 6,2 & $-60 \%$ \\
\hline 10 & $\begin{array}{l}\text { Eu consigo ensinar e fazer com que os trabalhadores aprendam, } \\
\text { pois uso exemplos sobre como as coisas funcionam na prática? }\end{array}$ & 7,2 & $-20 \%$ \\
\hline 11 & $\begin{array}{l}\text { Eu faço uma avaliação cognitiva (aquisição de conhecimento) da } \\
\text { aprendizagem, no meio e no final do treinamento para reavaliar o } \\
\text { que foi aprendido e busco estas respostas dos aprendizes? }\end{array}$ & 3,6 & $-100 \%$ \\
\hline 12 & $\begin{array}{l}\text { Eu busco a participação através de perguntas, em alguns momentos } \\
\text { para todo o grupo e em outros individualmente? }\end{array}$ & 5,3 & $-70 \%$ \\
\hline 13 & $\begin{array}{l}\text { Eu fico muito atento para perceber se o trabalhador está perdendo o } \\
\text { interesse no assunto e quando percebo desperto novamente o seu } \\
\text { interesse? }\end{array}$ & 6 & $-90 \%$ \\
\hline 14 & $\begin{array}{l}\text { Eu faço exercícios e trabalhos em grupos, gerando desafios, análise } \\
\text { e reflexão com relação aos temas abordados no treinamento? }\end{array}$ & 3,7 & $-100 \%$ \\
\hline \multirow[t]{2}{*}{15} & $\begin{array}{l}\text { Eu utilizo técnicas e ferramentas de cunho andragógicas na } \\
\text { realização dos meus treinamentos? }\end{array}$ & 2,7 & $-100 \%$ \\
\hline & MÉDIA & 5 & $-72 \%$ \\
\hline
\end{tabular}

Fonte: Elaborado pelo Autor (2019)

O cálculo do NPS é feito da seguinte forma: os valores 7 e 8 são considerados neutros. Os respondentes que responderam 9 e 10 são chamados de Promotores e os abaixo de 06 são considerados detratores. O valor do NPS é obtido através da seguinte fórmula: (Promotores - Detratores) / número total da amostra (PRADO, 2019). 
Foi possível observar através dos resultados que o NPS da amostra foi bastante ruim, pois todos os resultados estavam abaixo de $0 \%$. Isso significa que os instrutores entrevistados precisam investir melhor em práticas andrológicas nos seus treinamentos. A média geral do resultado do presente estudo foi $-72 \%$ de NPS. Conclui-se que uma ação emergencial é necessária para melhorar esse quadro na empresa (PRADO, 2019).

Quanto à média das respostas, foi percebido que o ponto de maior necessidade de melhoria foi o item 04 . Os instrutores precisam aprender a identificar o estilo de aprendizagem dos alunos, ou seja, os que são visuais, auditivos ou cinestésicos. Também foi interessante observar as questões 14 e 15. Percebeu-se que os instrutores não utilizam técnicas e ferramentas de cunho andragógico na realização dos seus treinamentos e que também realizam de forma muita tímida exercícios e trabalhos em grupos, gerando desafios, análise e reflexão com relação aos temas abordados no treinamento.

Quanto às respostas obtidas que foram satisfatórias, destacam-se os itens 07 e 10, os quais se referem à demonstração ao trabalhador de que o assunto que ele irá aprender vai atender suas necessidades básicas e será de aplicação imediata e em situações reais. A questão 10 se refere ao uso de exemplos para realização dos treinamentos. Isso é de grande importância no contexto empresarial e auxilia no processo de ensino/aprendizagem.

Entretanto, há que se estabelecer o uso de melhores técnicas e ferramentas de ensino, sobretudo do ponto de vista andragógico, para estimular melhor os educandos de forma, que seja possível alcançar melhores resultados na aprendizagem e que ela seja feita de forma eficaz e efetiva.

\section{CONSIDERAÇÕES FINAIS}

Colaboradores lidam com problemas reais em seu cotidiano. Por isso, mais do que qualquer outro incentivo, eles precisam ter certeza de que o treinamento ao qual serão submetidos traz uma resposta a essas necessidades. Esse modelo também entende que cada um assimila as informações em seu próprio ritmo e apresenta uma jornada própria de conhecimento. 
Tendo em vista o objetivo geral do presente estudo, que é identificar o nível de aproximação/distanciamento da atuação dos instrutores em Segurança do Trabalho quanto às técnicas andragógicas, o presente estudo concluiu que boa parte dos instrutores não tem conhecimento de técnicas andragógicas de aprendizado e é necessário que, além de uma boa oratória e bom conteúdo em seus treinamentos, os instrutores sejam capacitados para atuar em um processo de educação ligado aos princípios e pressupostos andragógicos, adaptando desta forma, o processo de ensino às necessidades dos alunos.

Quanto aos objetivos específicos, que eram analisar a utilização de técnicas e métodos no processo de ensino aprendizagem a partir da visão andragógica; e apresentar vantagens quanto ao uso adequado e estruturado da metodologia andragógica nos treinamentos e capacitações dentro das empresas, foi percebido que as técnicas andragógicas facilitam o ambiente educacional de forma ímpar. Através da Andragogia, os alunos sentem que suas experiências de vida são incluídas no método de aprendizado e isso é fundamental para que eles vejam o sentido no que está sendo ensinado.

Para alcançar um bom ambiente de ensino/aprendizagem com técnicas andragógicas, as empresa que desejam alcançar bons resultados nos processos de capacitação e qualificação do seus trabalhadores, quanto as questões ligadas a segurança no trabalho, e é bom lembrar que estamos falando de vidas que estão diariamente expostas aos riscos de acidentes, devem ter preocupação genuína com este assunto e garantir que seus instrutores sejam capacitados na metodologia andragógica, a fim de gerar o conhecimento necessário e adequado aos trabalhadores, especialmente quanto à aproximação do ensino das vivências e experiências dos aprendizes.

\section{REFERÊNCIAS}

BARROS, Rosanna. Revisitando Knowles e Freire: Andragogia versus pedagogia, ou O dialógico como essência da mediação sociopedagógica. In: Educação e Pesquisa, São Paulo, v. 44, p. 1-19, 2018. 
BECK, Caio. Pedagogia e Andragogia são iguais?Andragogia Brasil. 2014. Disponível em: < https://andragogiabrasil.com.br/pedagogia-e-andragogia-saoiguais/ > Acesso em 18/07/2019 às 11:05.

BRASIL. LEI № 6.514, DE 22 DE DEZEMBRO DE 1977. Altera o Capítulo V do Titulo II da Consolidação das Leis do Trabalho, relativo a segurança e medicina do trabalho e dá outras providências. Disponível em:

<http://www.planalto.gov.br/ccivil_03/LEIS/L6514.htm> acesso em 18/08/2019 às $12: 12$.

BRESSIANI, Lucia; ROMAN, Humberto Ramos. A utilização da andragogia em cursos de capacitação na construção civil. 2016. Tese de Doutorado. Tese (Doutorado em Engenharia Civil)-Universidade Federal de Santa Catarina, Florianópolis, 2016.

CHAN, Sang. Applications of andragogy in multi-disciplined teaching and learning. Journal of adult education, v. 39, n. 2, p. 25-35, 2010.

DE CARVALHO, Jair Antonio et al. Andragogia: considerações sobre a aprendizagem do adulto. Ensino, Saúde e Ambiente, São Paulo, v. 3, n. 1, 2010.

GIL, A. C. Métodos e técnicas de pesquisa social.São Paulo: Atlas, 1999.

JOHNSON, R. Burke; ONWUEGBUZIE, Anthony J.; TURNER, Lisa A. Toward a definition of mixed method research. Journal of Mixed Methods Research, v.1, n.2, p. 112-133, 2007.

MERCURIO, Treinamentos. Andragogia e sua importância no desenvolvimento de pessoas. 2017. Disponível em: < https://www.mercuriotreinamento.com/leiaconosco/andragogia-e-sua-importancia-no-desenvolvimento-de-pessoas > Acesso em 18/07/2019 às 11:05.

MINAYO, M. C. S. Pesquisa social: teoria, método e criatividade. 22 ed. Rio de Janeiro: Vozes, 2003.

PRADO, Michele. NPS: como grandes empresas medem a satisfação de seus clientes. 2019. Disponível em: < https://www.mandae.com.br/blog/nps-o-que-e-ecomo-calcular-o-net-promoter-score/ > Acesso em 18/07/2019 às 09:45.

TARDIF, M. Saberes profissionais dos docentes e conhecimentos universitários: elementos para uma epistemologia da prática profissional dos professore e suas consequências em relação à formação para o magistério. Revista Brasileira de Educação, Jan/Fev/Mar/Abr, n. 13, 2000. 